\title{
DESAFIOS DA PESQUISA INTERDISCIPLINAR: AS CIÊNCIAS SOCIAIS COMO INSTRUMENTOS DE “VIGILÂNCIA EPISTEMOLÓGICA" NO CAMPO DOS ESTUDOS SOCIOJURÍDICOS
}

\author{
CHALLENGES OF INTERDISCIPLINARY RESEARCH: SOCIAL \\ SCIENCES AS INSTRUMENTS OF “EPISTEMOLOGICAL \\ SURVEILLANCE" IN THE FIELD OF SOCIO-LEGAL STUDIES
}

RESUMO: Este artigo tem o intuito de ressaltar a importância da pesquisa interdisciplinar para a compreensão da regulação jurídica em um contexto social hipercomplexo. Para tanto, em primeiro lugar, analisa as dificuldades e os desafios ínsitos ao desenvolvimento da interdisciplinaridade. Em seguida, propõe que os "estudos sociojurídicos" sejam definidos como um campo interdisciplinar em que contribuições provenientes das mais diversas áreas das ciências sociais podem ser apropriadas pelos juristas para a compreensão mais consequente da regulação jurídica. Contudo, considerando a especificidade assumida pelos aportes teóricos de outras disciplinas no campo dos "estudos sociojurídicos", propõe que as ciências sociais sejam entendidas, sobretudo, como instrumentos de "vigilância epistemológica" no âmbito desses estudos.

Palavras-Chave: Estudos Sociojurídicos; Interdisciplinaridade; Regulação Jurídica; Epistemologia; Vigilância Epistemológica.

ABSTRACT: This paper intends to emphasize the importance of interdisciplinary research for the understanding of legal regulation in a hypercomplex social context. To do so, first, it analyzes the difficulties and challenges inherent in the development

1 Professor Doutor da Faculdade de Direito da Universidade de São Paulo (FD/USP) e Professor Associado da Faculdade de Direito da Universidade Presbiteriana Mackenzie. Contato: ovbf@usp.br. 
of interdisciplinarity. Then, the paper conceives "socio-juridical studies" as an interdisciplinary field in which contributions from the most diverse areas of the social sciences can be appropriated by jurists for the development of more consistent comprehension of legal regulation. However, considering the specificity assumed by the theoretical contributions of other disciplines in the field of "socio-juridical studies", it proposes that the social sciences be understood, above all, as instruments of "epistemological surveillance" within these studies.

KEYWORDS: Socio-Legal Studies; Interdisciplinarity; Legal Regulation; Epistemology; Espistemological Surveillance.

\section{INTRODUÇÃo}

A complexidade da sociedade hodierna tem demandado cada vez mais abordagens pautadas pela interdisciplinaridade, uma vez que estas, ao promoverem um entrecruzamento rico e variado de perspectivas, estariam mais aptas à compreensão adequada das questões intrincadas com que se defrontam. ${ }^{2}$ Nesse sentido, Jacques Commaille, inspirado em Immanuel Wallerstein, alude à necessidade de promoção de uma "cultura da ciência social" em lugar das divisões disciplinares convencionais. ${ }^{3}$ Entretanto, apesar de suas evidentes virtudes, a pesquisa interdisciplinar ainda é, grosso modo, bastante limitada e, quando existente,

\footnotetext{
${ }^{2}$ Nesse particular, é fundamental, desde logo, diferenciar interdisciplinaridade, pluridisciplinaridade, multidisciplinaridade e transdisciplinaridade. Contrastando essas perspectivas, François Ost e Michel van de Kerchove ressaltam que, entre elas, apenas a interdisciplinaridade seria efetivamente consequente para o tratamento de questões complexas de modo a evitar, de um lado, a mera justaposição de perspectivas (algo que ocorreria com a pluridisciplinaridade e com a multidisciplinaridade) e, de outro, a constante subversão dos pontos de vista de cada disciplina com o propósito de produção de um "saber autônomo" (situação à qual conduz a pesquisa transdisciplinar). Cf. François Ost e Michel Van de Kerchove (1991, p. 77-78). No que tange à relação entre diferenciação e complexidade social, ver, por exemplo: Niklas Luhmann (2007, p. 100 e ss.; 1995, p. 191-194).

3 Referindo-se às fronteiras disciplinares ainda vigentes no âmbito das ciências sociais, Jacques Commaille ressalta que "ce qui maintient les frontières tient moins à des raisons de connaissance qu'à des considérations institutionnelles et corporatistes [...] il reste à penser ... une 'culture de la science sociale' en lieu et place de disciplines de sciences sociales appartenant à un passé révolu" (COMMAILLE, 2010, p. 38). Sobre essa questão, ver também: Commaille (1994, p. 22 e ss).
} 
marcada por certo ecletismo e por dificuldades de implementação, especialmente em contextos acadêmicos em que interesses corporativos, muitas vezes sem efetiva qualidade epistemológica, engendram barreiras inexpugnáveis a uma troca estruturada de conhecimentos.

É comum que os juristas, ciosos de suas taxinomias e classificações dogmáticas, tendam a ser refratários a esse intercurso frutífero que a interdisciplinaridade pode ensejar. Por outro lado, os cientistas sociais, não poucas vezes, ao serem corrosivamente críticos e desqualificarem as formulações conceituais dos juristas, não apenas obstaculizam a construção de um "campo comum" para a discussão de problemas complexos, como, inclusive, em alguns casos, acabam por comprometer o alcance de suas próprias abordagens na medida em que delas excluem um horizonte prático e conceitual que, com todas as dificuldades que possa ter, é essencial à compreensão da regulação jurídica. ${ }^{4}$ É bem verdade que a interdisciplinaridade não deve ser confundida com a abertura indiscriminada de campos disciplinares diversos e com a "hibridação temerária de métodos". ${ }^{5}$

Ao sublinhar os expressivos esforços realizados pelas diversas disciplinas envolvidas na empreitada interdisciplinar, André-Jean Arnaud já identificava, no início da década de 1990, uma situação de cacofonia no âmbito dos "estudos sociojurídicos" (ARNAUD, 1992, p. 25-26). Cabe notar que, embora tenha sido grande entusiasta e incansável promotor da pesquisa interdisciplinar, Arnaud era refratário às soluções artificialmente unificadoras e aos sincretismos teóricos. Insistia, assim, no fato de que o desenvolvimento desse tipo de pesquisa demandaria, entre outras coisas, novos fundamentos epistemológicos, cujos traços, aliás, procurava mapear mediante a mobilização de autores como Gaston Bachelard, Jean Piaget, Karl Popper, Thomas Kuhn, Jürgen Habermas, Michel Foucault, Pierre Bourdieu, Boaventura de Sousa Santos e, até mesmo, Georges Canguilhem (ARNAUD, 1992, p. 27-37).

Seja como for, apesar de todas as dificuldades ínsitas à realização da pesquisa jurídica interdisciplinar, não é possível desconsiderar os expressivos esforços que se desenvolvem nesse sentido e os instigantes resultados que deles derivam. Logo, desde que tomadas as precauções para se evitar um "ecumenismo ingênuo", a

\footnotetext{
${ }^{4}$ A respeito, ver, por exemplo, José Reinaldo de Lima e Roberto Freitas Filho (2014, p. 99) e Orlando Villas Bôas Filho (2017a, p. 1115).

${ }^{5}$ Étienne Le Roy (2013, p. 194), referindo-se a Jacques Caillosse, alude às cautelas necessárias para que sejam evitadas as "hybridations méthodologiques hasardeuses". A respeito, ver também Villas Bôas Filho (2017a, p. 1115).
} 
promoção de uma "pesquisa de complementaridades", nos termos em que Jacques Commaille a define, afigura-se como muito frutífera (COMMAILLE, 2015, p. 25; 2016, p. 01-12). Aliás, algumas questões, em virtude de sua complexidade, fazem com que uma abordagem desse tipo, em que ocorre a interação entre diversos campos disciplinares, se torne indispensável. ${ }^{6}$ Em uma expressiva obra, Michael Hardt e Antonio Negri enfatizam esse aspecto. Realçando a complexidade do assunto de que tratam - o império -, os autores sustentam a necessidade de assunção de uma perspectiva interdisciplinar, salientando, inclusive, a tendência de desmoronamento das compartimentalizações disciplinares. ${ }^{7}$

Ora, sendo a interdisciplinaridade uma prática cujos benefícios são aparentemente irrefutáveis, cabe perguntar em que termos ela pode ser efetivamente realizada no âmbito dos "estudos sociojurídicos", tal como estes serão aqui definidos. Trata-se de questão da maior importância diante do progressivo desenvolvimento de estudos críticos no Brasil, ${ }^{8}$ uma vez que a complexidade temática desses estudos demanda a assunção de uma perspectiva interdisciplinar. O último congresso internacional promovido pela Associação Brasileira de Pesquisadores em Sociologia do Direito (ABraSD), no mês de setembro de 2018, na Faculdade de Direito da Universidade de São Paulo, ilustra exemplarmente essa situação. Nesse evento, além das conferências, mesas e minicursos, diversos Grupos de Pesquisa abordaram

${ }^{6}$ Nesse particular, à guisa de exemplo, poder-se-ia indagar acerca da possibilidade de compreensão adequada de temas como o do "pluralismo jurídico", das relações entre direito e política, das "formas alternativas de resolução de conflito" ou da "governança", sem conjugar aportes das análises antropológica, sociológica, política e histórica. No que tange a esses temas, os trabalhos de maior sofisticação sugerem justamente a necessidade da interdisciplinaridade. A respeito, em caráter meramente ilustrativo, ver Arnaud (1997, p. 11-35; 2003; 2004; 2014), Delmas-Marty (2006; 2010), Hespanha (2012), Le Roy (1999; 2007, p. 341-351 ; 2013, p. 193-208), Moore (2014, p. 05-18), Rouland (1988; 1995; 2003), Vanderlinden $(1995$; 2009, p. 25-76). Para a tematização dessas questões, no Brasil, mediante a mobilização desses autores, ver Villas Bôas Filho (2014, p. 314-317; 2015a, p. 56-75; 2015b, p. 159-195; 2016a, p. 670-706; 2016b, p. 145-171; 2017a, p. 1112-1162; 2018b, p. 491-520).

7 A respeito, Hardt e Negri (2000, p. XVI) afirmam que "in writing this book we have tried to the best of our abilities to employ a broadly interdisciplinary approach. Our argument aims to be equally philosophical and historical, cultural and economic, political and anthropological. In part, our object of study demands this broad interdisciplinarity, since in Empire the boundaries that might previously have justified narrow disciplinary approaches are increasingly breaking down".

8 Trata-se de tendência notada, ainda que informalmente, por expressivos autores brasileiros. A respeito, ver, por exemplo: Oliveira (2015, p. 169). 
múltiplas questões, cujas diversidade e complexidade evidenciam a necessidade da interdisciplinaridade. ${ }^{9}$

\section{OS DESAFIOS DA PESQUISA INTERDISCIPLINAR: ENTRE CACOFONIA E CARICATURA}

As dificuldades da pesquisa interdisciplinar são particularmente realçadas por André-Jean Arnaud. Para ele, o problema fundamental nessa seara consiste no fato de os pesquisadores de disciplinas distintas tenderem a constituir o objeto segundo o cânon de suas respectivas áreas de proveniência. Nesse sentido, desde o início da década de 1990, diagnosticava, como mencionado, uma situação de cacofonia no âmbito dos "estudos sociojurídicos". ${ }^{10}$ Analogamente, Celso Fernandes Campilongo, aludindo, aliás, à perspectiva de Arnaud, também assevera, e com razão, que "o trabalho de colaboração interdisciplinar nas pesquisas jurídicas constantemente revela um 'sentimento de impotência de como controlar a complexidade de um fenômeno ou de uma realidade que cada um aborda com uma linguagem diferente'" (CAMPILONGO, 2000, p. 18). Em uma situação como essa, em vez de diálogo, o que geralmente se observa é o entrechoque de monólogos, ou seja, ruído.

${ }_{9}^{9}$ Os Grupos de Pesquisa do IX Congresso da Associação Brasileira de Pesquisadores em Sociologia do direito foram, pela ordem, os seguintes: GP1 - Direito, pluralismo e sociologia do constitucionalismo; GP2 - Novas perspectivas para a teoria dos sistemas: teoria crítica e organizações; GP 3 - Direito, racismo e desigualdades sociais; GP 4 - Direito e inclusão social; GP 5 Gênero, sexualidade, crime e violência; GP 6 - Direito e a economia da imigração; GP 7 - Linguagem e direito; GP 8 - Biopoder, violência e direitos humanos; GP 9 - Sociologia da infância; GP 10 Teoria e pesquisa sociológica do direito; GP 11 - Direitos humanos, saúde e sociologia: quais as teorias aplicadas para a contemporaneidade?; GP 12 - Sociologia do processo e da administração de conflitos; GP 13 - Direito e transformação social a partir de um teoria constitucional feminista; GP 14 - Metodologia da pesquisa e do ensino da sociologia jurídica; GP 15 - Judicialização, crises e reformas; GP 16 - Análise sociojurídica de políticas públicas; GP 17 - Sociologia jurídica da transnacionalização; GP 18 - Inclusão/exclusão, organizações e políticas públicas; GP 19 - Pesquisas sócio-históricas em saberes e práticas do sistema de justiça criminal; GP 20 - Crítica do direito: teoria, sociologia, dogmática e pesquisa; GP 21 - A (des)constituição de gênero no pós-88; GP 22 Propriedades em transformação. Para uma descrição dos grupos, ver: <https://www.doity.com.br/ixcongresso-internacional-da-abrasd--associacao-brasileira-de-pesquisadores-em-sociologia-dodireit/>.

${ }^{10}$ Diagnosticando a situação de cacofonia no âmbito dos "estudos sociojurídicos", Arnaud ressaltava que "la pierre sur laquelle achoppa et achoppe encore l'interdisciplinarité consiste dans l'impossibilité qu' on les tenants des diverses disciplines, de s'entendre sur l'objet - Droit. Chacun le constitue selon les canons propres à sa formation disciplinaire. Pour l'instant, c'est encore la cacofonie" (ARNAUD, 1992, p. 25). 
Por outro lado, ao se tentar elidir essa situação de cacofonia, é preciso também evitar que a pesquisa interdisciplinar redunde em uma "hibridação temerária de métodos" da qual deriva o "ecumenismo ingênuo" criticado por Jacques Commaille (2016, p. 09), uma vez que isso resultaria em uma caricatura das disciplinas em interação. A respeito, Jacques Caillosse alerta para o risco da mistura indiscriminada de gêneros, mediante a celebração acrítica da hibridação metodológica. Para esse autor, não obstante as fronteiras disciplinares possam, comumente, parecer esclerosadas e contraproducentes, o fato é que a vontade ingênua de aboli-las seria insensata na medida em que poderia produzir um território intelectual totalmente desestruturado e desprovido de consistência. ${ }^{11}$ Apesar de seu caráter profícuo, a interdisciplinaridade não deve ensejar a desconsideração da especificidade das perspectivas postas em interação.

Todavia, é preciso notar que a possibilidade de a pesquisa interdisciplinar redundar em cacofonia ou caricatura decorre das dificuldades inerentes a essa empreitada. ${ }^{12}$ Preliminarmente, como ressaltam Antoine Bailleux e François Ost, a prática interdisciplinar sempre pode se desvirtuar quando uma das disciplinas em interação assume posição central e instrumentaliza as demais. ${ }^{13}$ A propósito, é justamente por isso que André-Jean Arnaud e María José Fariñas Dulce, ao conceberem os "estudos sociojurídicos" como um campo de pesquisa interdisciplinar, afirmam que "qui dit collaboration dit équilibre" (ARNAUD; FARIÑAS DULCE, 1998, p. 162). Além disso, é importante considerar o fato de que a apropriação que os juristas realizam de aportes provenientes de outras áreas não deve fazer com que eles percam de vista a especificidade de sua própria perspectiva. Assim, como bem o notam Huges Dumont e Antoine Bailleux, por mais que o jurista se torne apto a explorar e se apropriar de estudos provenientes das ciências sociais,

11 Segundo Caillosse (2011, p. 204), “il n’a nullement été question de mélanger les genres ou de célébrer, pour elles-mêmes, les vertus de l'hybridation méthodologique! Autant les cloisonnements disciplinaires apparaissent souvent sclérosants et contre-productifs, autant la volonté naïve de les abolir serait proprement insensée: elle laisserait voir un territoire intellectuel déstructuré et dépourvu de toute consistance. L'essentiel ne doit surtout pas être oublié: il appartient à chaque discipline scientifique de déterminer son objet, du seul point de vue des questions qu'elle se pose et des méthodes qu'elle privilégie pour les mettre à jour".

${ }^{12}$ Como observam François Ost e Michel van de Kerchove (1991, p. 78), a interdisciplinaridade, apesar de suas vantagens (especialmente quando comparada com a multidisciplinaridade/pluridisciplinaridade ou com a transdisciplinaridade), é "relativamente instável".

${ }^{13}$ Segundo Bailleux e Ost (2013, p. 43), “la pratique interdisciplinaire est toujours menacée d'opérer au service unique d'une discipline qui se place en position centrale, posant les questions et suggérant les réponses à des disciplines vouées alors à 'l'ancillarité'". 
isso não implica que ele reproduza o tipo de pesquisa desenvolvido nessas respectivas áreas. ${ }^{14}$

Essa última questão conduz à necessidade de considerar a especificidade assumida pelos aportes provenientes das ciências sociais no âmbito da pesquisa jurídica. Nesse particular, é fundamental ter clareza de que, ao mobilizarem distintos enfoques, os juristas (que não costumam ter formação interdisciplinar) os ressignificam diante do manejo que deles fazem. É por esse motivo que Hugues Dumont e Antoine Bailleux sustentam a ideia de "aberturas limitadas" por intermédio das quais a perspectiva jurídica seja capaz de se beneficiar de teorias, métodos e conceitos das ciências sociais, sem que isso, entretanto, implique a desconsideração do perfil das pesquisas postas em interação. ${ }^{15}$ Não cabe ao jurista, portanto, efetuar um simples exercício de mimetismo estéril relativamente ao que se desenvolve em outras áreas, pois isso o conduziria a descambar para uma banalização caricata daquilo que nelas se realiza. Ao contrário, para ser sólida, a construção de um campo de estudo interdisciplinar que tenha por objeto a regulação jurídica precisa ter em consideração o terreno pantanoso em que deita seus alicerces. ${ }^{16}$

14 A respeito, Dumont e Bailleux (2010, p. 286) asseveram, com razão, que "la construction d'une science $\mathrm{du}$ droit interdisciplinaire et critique aussi ambitieuse appelle la collaboration notamment des juristes, des politologues, des sociologues et des philosophes. Pour mener à bien une approche scientifique du droit réellement externe, tout étant avertie du point de vue interne, il faut être un théoricien du droit professionnel capable de jongler aussi bien avec la doctrine juridique qu'avec au moins certains des paradigmes de la sociologie, de la science politique et de la philosophie. Le juriste auquel nous nous adressons et que nous sommes nous-mêmes ne présente pas ce profil. Il ne peut donc prétendre contribuer à la construction de cette science du droit que par des ouvertures limitées vers les sciences sociales, au départ de son approche qui sera d'abord et principalement d'ordre juridique, c'est-à-dire menée du point de vue interne à celui-ci".

${ }^{15}$ A respeito, Dumont e Bailleux (2010, p. 286-287) destacam que "ces ouvertures, à condition qu'elles soient rigoureuses et articulées avec l'approche doctrinale sans confusion des genres, n'en devraient pas moins être très précieuses aussi bien pour l'enrichissement qu'elles procurent au travail doctrinal que pour les ponts qu'elles bâtissent avec les sciences sociales dans la perspective de cette science du droit-carrefour interdisciplinaire".

16 Cumpre notar que este artigo pretende apenas sublinhar as dificuldades ínsitas à pesquisa interdisciplinar para, a partir daí, propor que as ciências sociais figurem como instrumentos de "vigilância epistemológica" nos "estudos sociojurídicos". Seu propósito não é, portanto, fornecer um modelo a ser seguido para a realização desse tipo de pesquisa. Para uma proposta que se esboça nesse sentido e apresenta grande potencial heurístico, ver Bailleux e Ost (2013, p. 43) e Ost (2009, p. 95-101). 


\section{PREMISSAS AO DESENVOLVIMENTO DA PESQUISA INTERDISCIPLINAR CONSISTENTE: A SUPERAÇÃO DOS “MODELOS INGÊNUOS" MEDIANTE A ASSUNÇÃO DE UMA PERSPECTIVA CONSTRUTIVISTA}

Em uma análise que abrange relevantes aspectos epistemológicos concernentes ao conhecimento do direito, Antoine Bailleux e François Ost criticam as perspectivas teóricas que, presas a pressupostos ontológicos, concebem a realidade como composta por domínios previamente estabelecidos, em meio aos quais estaria o jurídico. Assim, sublinhando que cada disciplina constrói o real de acordo com o seu ponto de vista, os autores examinam o que designam de "modelo ingênuo de monodisciplinaridade" (modèle naïf de la monodisciplinarité) e de "modelo ingênuo de interdisciplinaridade" (modèle naïf de la interdisciplinarité), contrastando-os com o que denominam de "modelo crítico de monodisciplinaridade" (modèle critique de monodisciplinarité) e de "modelo crítico de interdisciplinaridade" (modèle critique de l'interdisciplinarité). ${ }^{17}$

Conforme Antoine Bailleux e François Ost, a característica fundamental dos "modelos ingênuos" - tanto monodisciplinar como interdisciplinar - é a pressuposição do objeto como um dado natural estabelecido a priori (BAILLEUX; OST, 2013, p. 37). Nessa perspectiva, tanto "direito" como "sociedade" seriam considerados imanentes à realidade e, por isso, dotados de certa essencialidade a ser apreendida pelas abordagens científicas, motivo pelo qual ao objeto "direito", já previamente dado, corresponderia uma "ciência do direito" e à "sociedade", também concebida como dotada de uma substancialidade natural, corresponderiam as "ciências sociais". André-Jean Arnaud designa essa tendência de assunção de pressupostos ontológicos, por parte dos analistas, de "epistemologia positivista" e enfatiza a dificuldade de, a partir dela, se implementar uma efetiva articulação interdisciplinar. ${ }^{18}$

\footnotetext{
17 Antoine Bailleux e François Ost (2013, P. 37), referindo-se a autores como Niklas Luhmann, Gunther Teubner e Julien Pieret, ressaltam que "chaque discipline a vocation à parler de tout de son point de vue, de sorte qu'il n'y pas d'objet en soi, mais seulement un objet 'droit' construit par les sciences juridiques, ou par les sciences économiques, ou par les sciences anthropologiques". Acerca dos autores citados por Bailleux e Ost, ver, por exemplo Niklas Luhmann (1993, p.09-37), Julien Pieret (2013, p. 139-148), Gunther Teubner (1989, p. 727-757).

18 A respeito, Arnaud (1992, p. 21) ressalta que "l'épistémologie positiviste est fondée sur quelques axiomes qui ne permettent pas de franchir le fossé qui existe entre le Droit et les sciences sociales.
} 
Em lugar desses "modelos ingênuos", Antoine Bailleux e François Ost propõem o que chamam de "modelos críticos" de monodisciplinaridade e de interdisciplinaridade. Na visão desses autores, o que fundamentalmente diferencia os modelos "ingênuos" dos "críticos" é o construtivismo radical que caracteriza estes últimos. Assim, os "modelos críticos" partem da premissa de que cada ciência não apenas cria o seu objeto, mas também a imagem do que o envolve, ou seja, de seu contexto $\left(.{ }^{19}\right.$ Nessa perspectiva, a inocência dos "modelos ingênuos" seria superada em virtude de dois aspectos fundamentais e reciprocamente relacionados: a) o fato de cada disciplina tomar consciência de que ela é inevitavelmente conduzida a afirmar algo acerca do contexto de seu objeto, uma vez que este não é concebido como um dado natural fixado a priori; b) o caráter convencional (e, portanto, inexoravelmente situado) do que cada disciplina pode dizer acerca do contexto do objeto (BAILLEUX; OST, 2013, p. 39).

Não cabe aqui discutir a integralidade da proposta de Antoine Bailleux e François Ost, mas apenas o que, na visão deles, configuraria um modelo consequente de interdisciplinaridade, caracterizado, como visto, pela assunção de uma perspectiva construtivista que renuncia a postulados ontológicos. Uma abordagem consequente dessa questão demandaria a tematização dos fundamentos epistemológicos necessários à passagem dos modelos "ingênuos" aos "críticos", o que, entretanto, exigiria digressões incompatíveis com os limites e os propósitos deste artigo. À guisa de mera referência, vale notar que, ao contrastar o que designa de "epistemologia positivista" e "epistemologia constitutiva", André-Jean Arnaud sintetiza magistralmente o que está implicado em uma tal passagem, destacando, especialmente, os seguintes aspectos: a) o pressuposto de Gaston Bachelard de que nada é dado, e sim construído; b) a representatividade da experiência no lugar do "postulado da realidade da realidade"; c) a substituição do princípio da objetividade pelo da projetividade. ${ }^{20}$

Ontologiquement, l'épistémologie positiviste postule à la fois la dualité de l'objet et du sujet, et la réalité du réel. Le but de la science consiste ainsi à découvrir la vérité en décrivant la réalité conçue comme expérience sensible. [...] Selon le postulat déterministe, qui est également au fondement de l'épistémologie positiviste, le réel est susceptible de connaissance, l'univers fonctionnant selon des lois qu'il convient seulement de découvrir pour parvenir à la science parfaite"..

19 Referindo-se a esses "modelos críticos", Bailleux e Ost (2013, p. 39) afirmam que neles "chaque science crée non seulement son objet mais aussi une image de ce qui l'entoure, son contexte". A respeito, ver, especialmente Arnaud (2013, p. 45-53) e Commaille (2013, p. 62-69).

${ }^{20}$ A respeito, ver também Arnaud (1992, p. 27-37). Analogamente, ver Lugan (2012, p. 104).

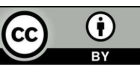




\section{A INTERDISCIPLINARIDADE COMO ABERTURA DOS JURISTAS AOS APORTES DAS “CIÊNCIAS SOCIAIS"}

Hugues Dumont e Antoine Bailleux, enfatizando os aportes indispensáveis das ciências sociais para a compreensão do fenômeno jurídico, propõem o que denominam de "esboço de uma teoria das aberturas interdisciplinares acessíveis aos juristas". Ao discutirem a possibilidade de uma abertura interdisciplinar realista, os autores realçam a importância de os juristas se servirem de estudos desenvolvidos na antropologia, na filosofia, na história, na ciência política e na sociologia para o enriquecimento de sua própria concepção da regulação jurídica. Ressaltam, entretanto, que essa apropriação não implica supor que os juristas farão, eles próprios, estudos de maior relevância no âmbito das diversas disciplinas das quais se valem. ${ }^{21}$ Portanto, explorar aportes de outras áreas não implica se converter em antropólogo, economista, filósofo, historiador, cientista político ou sociólogo, mas desenvolver uma abordagem que, beneficiada pela interdisciplinaridade, seja capaz de propiciar uma compreensão mais consistente da regulação jurídica.

É nesse sentido que, pretendendo esboçar uma "ciência interdisciplinar e crítica do direito", Hugues Dumont e Antoine Bailleux procuram distinguir três "círculos concêntricos": direito, como objeto de estudo; doutrina jurídica; e ciência do direito. ${ }^{22}$ Não se trata aqui de reconstruir a proposta dos autores, mas apenas de sublinhar o quanto a "ciência do direito", por eles proposta como expressão do terceiro "círculo concêntrico", que aos dois primeiros abrange, é tributária de uma perspectiva interdisciplinar. Dumont e Bailleux são, aliás, taxativos em salientar que, em oposição a uma visão que qualificam de "positivista" - e, como tal, portadora de uma tematização monodisciplinar do direito -, a "ciência do direito" por eles propugnada deveria assumir uma metodologia crítica e interdisciplinar. ${ }^{23}$ Tratar-se-ia, assim, de

${ }^{21}$ Nesse particular, Dumont e Bailleux (2010, p. 276-277) ressaltam que o fundamental é que o jurista seja capaz de "comprendre et exploiter des études sociologiques, politologiques, historiques ou philosophiques, sans pour autant supposer qu'il serait capable de faire lui-même en première ligne un travail relevant de ces disciplines".

22 Segundo Dumont e Bailleux (2010, p. 277), “il consiste à distinguer trois cercles concentriques. Le premier cercle forme l'objet d'étude de ce que l'on appelle communément la doctrine. Celle-ci forme le deuxième cercle qui entoure le premier. La science du droit, troisième cercle, a pour particularité d'englober les deux premiers".

23 A respeito, François Ost e Michel van de Kerchove (1991, p. 78) consideram que no bojo de uma "science interdisciplinaire du droit, la théorie du droit est appelée à jouer un rôle déterminant qui consiste a opérer le rapprochement ou la traduction des deux jeux de langage en présence: celui de la dogmatique, d'une part, celui des sciences sociales, d'autre part". Apesar de partir de outros pressupostos, Niklas Luhmann propõe algo semelhante. A respeito, ver, especialmente: Luhmann 
uma abordagem que, para os autores, consignaria um "ponto de vista externo" que, apesar de se ligar a uma finalidade essencialmente cognitiva e não prática, levaria em consideração seriamente o "ponto de vista interno" da doutrina (segundo "círculo concêntrico"). ${ }^{24}$ Tal empreitada, entretanto, demandaria, como destacam os autores, a colaboração entre juristas, filósofos, politólogos, sociólogos etc. ${ }^{25}$ É nesse sentido que, inspirados pela obra de André-Jean Arnaud, aludem à ideia de uma "science du droit-carrefour interdisciplinaire" (DUMONT ; BAILLEUX, 2010, p. 287).

\section{Os “ESTUDOS SOCIOJURÍDICOS” COMO CAMPO INTERDISCIPLINAR}

A proposta de constituição de um "carrefour interdisciplinaire" para o estudo do direito foi formulada originalmente por Arnaud e consiste na pretensão de promover a pesquisa interdisciplinar mediante a construção de uma linguagem comum, sobre um mesmo objeto e com um propósito também comum. ${ }^{26}$ Sua obra se afigura, assim, como um "modelo de interdisciplinaridade", tal como acentua François Ost (2016, p. 01-03), ou como expressão paradigmática do que Jacques Commaille designa de "pesquisa de complementaridades". ${ }^{27}$ A empreitada de Arnaud na construção de um campo de pesquisa interdisciplinar encontra nos "estudos sociojurídicos" seu âmbito

(1993, p. 9-37 e 497-549). Para um exame introdutório da relação entre sociologia jurídica, teoria do direito e dogmática jurídica no pensamento de Niklas Luhmann, ver Gonçalves e Villas Bôas Filho (2013, p. 149-152).

${ }^{24}$ Para uma análise que, no âmbito da discussão francesa, porém com forte influência do pensamento de Herbert L. A. Hart, contrasta "doutrina jurídica" e "ciência jurídica", ver Chevallier (2002, p. 103120). A respeito, ver também Arnaud (1986, p. 139-141) e Ost e Van de Kerchove (1991, p. 67-80).

${ }_{25}$ Para Dumont e Bailleux (2010, p. 286), "la construction d'une science du droit interdisciplinaire et critique aussi ambitieuse appelle la collaboration notamment des juristes, des politologues, des sociologues et des philosophes. Pour mener à bien une approche scientifique du droit réellement externe, tout étant avertie du point de vue interne, il faut être un théoricien du droit professionnel capable de jongler aussi bien avec la doctrine juridique qu'avec au moins certains des paradigmes de la sociologie, de la science politique et de la philosophie".

${ }^{26}$ Referindo-se a esse projeto, Arnaud $(1988$, p. 07 ; 1998, p. 77) afirma que se trata de "l'élaboration des grandes lignes d'une Théorie du droit et de la société qui permette aux juristes et aux chercheurs en sciences sociales de travailler avec un langage commun sur un objet commun et dans un but commun". Arnaud (1991, p. 220), aliás, procurou introduzir essa questão na discussão brasileira mediante sua incorporação a uma coletânea de artigos que publicou em português.

${ }^{27}$ A respeito, Commaille (2015, p. 24), referindo-se à sua trajetória, se declara "de plus en plus militant d'une pluri et même d'une interdisciplinarité [...]". Propõe, assim, o que designa de "recherche de complémentarité". Sobre a interdisciplinaridade na obra de Arnaud, ver Villas Bôas Filho (2017b, p.323-343). Ver também Campilongo (2000, p. 157-160). 
próprio de desenvolvimento (ARNAUD, 1992, p. 18). ${ }^{28}$ Para esse autor, além de constituírem o local privilegiado para a pesquisa interdisciplinar, os "estudos sociojurídicos" possibilitariam o desenvolvimento de uma pesquisa distinta da "pura teorização" e do "dogmatismo estéril". ${ }^{29}$

André-Jean Arnaud e María José Fariñas Dulce (1998, p. 161), com o propósito de conceberem os "estudos sociojurídicos" como um campo de pesquisa interdisciplinar, mobilizam três hipóteses. Em primeiro lugar, ressaltam que esse campo constituiria um âmbito que congrega as investigações de pesquisadores provenientes de distintas formações disciplinares. Em segundo lugar, sustentam que a "descoberta" do "território" recoberto por esses estudos é balizada pela perspectiva do pesquisador, tendo em conta o local em que este, como observador, se situa. Por fim, asseveram que a possibilidade de que esse "território" possa ser considerado cientificamente como um "campo" (champ) no sentido em que as ciências sociais o definem..$^{30}$ Assumindo essas hipóteses como premissas na configuração desse gênero de estudos, os autores salientam a interdisciplinaridade como sua característica fundamental.

Por conseguinte, segundo André-Jean Arnaud (1994, p. 300), a expressão “estudos sociojurídicos" englobaria, genericamente, o conjunto dos pesquisadores interessados em uma abordagem social do direito. Tais estudos constituiriam, assim, um tipo de sociologia jurídica renovada, na qual as dimensões econômica e política seriam adicionadas às reivindicações realistas dos primeiros sociólogos jurídicos.

${ }_{28}$ Arnaud (1994, p. 300) ressalta, ademais, que: “par le terme 'études socio-juridiques' on englobe sous une expression générique l'ensemble des chercheurs intéressés par le plus petit commun dénominateur aux diverses tendances qui se sont fait jour depuis qu'on a osé parler de l'importance de l'apport potentiel, pour les juristes, d'une approche sociale du droit. On désigne donc par là une sorte de moyen terme entre toutes les lignées existantes qui préconisent un regard sur le droit qui ne néglige pas le contexte social global. Les études socio-juridiques constituent aujourd'hui une sorte de sociologie juridique renouvelée, où les dimensions économique et politique se sont ajoutées aux revendications réalistes des premiers sociologues juristes".

${ }^{29}$ Segundo Arnaud (1992, p. 18), "la discipline par où les chercheurs entendent précisément échapper tant à la pure théorisation qu'au dogmatisme stérile, se trouve aux confins de la politique, de la psychologie, de la sociologie et du Droit et se nomme, selon les lieux et les écoles, sociologie du Droit, sociologie juridique, Socio-legal studies, Law and Society studies, Law in context". No mesmo sentido, ver: Arnaud (2013, p. 45-47), Arnaud e Fariñas Dulce (1998, p. 23; 27 e 166), Delpeuch, Dumoulin e Galembert (2014, p. 09-10).

30 No que tange a essa última hipótese, é evidente a influência do pensamento de Pierre Bourdieu sobre os autores que, aliás, a ele se referem, logo adiante, ao qualificarem os "estudos sociojurídicos" como um “champ ouvert” (ARNAUD; FARIÑAS DULCE, 1998, p. 165). 
Contudo, de acordo com o autor, essa abordagem social do direito resultaria de uma ruptura epistemológica e, para explicitar o que nela está implicado, Arnaud (1992, p. 21-37) contrapõe, conforme mencionado, o que nomina de "epistemologia positivista" (consistente na atitude de técnicos a serviço de estratégias cujos propósitos lhes escapam) e de "epistemologia constitutiva" (que, em seu entendimento, seria suscetível de franquear acesso à realidade social com a qual os juristas se confrontam). Sem adentrar na análise que Arnaud faz desses dois tipos de epistemologia, cumpre notar que, em seu entendimento, somente o segundo deles possibilitaria o desenvolvimento de uma abordagem verdadeiramente interdisciplinar do direito. ${ }^{31}$

No entanto, como enfatizado, a interdisciplinaridade não é algo simples de implementar. Para André-Jean Arnaud, o maior problema à sua realização consistiria na dificuldade que os pesquisadores egressos de campos disciplinares distintos teriam em chegar a um acordo acerca do que é o Direito como objeto, uma vez que cada autor tende a constituí-lo segundo os cânones próprios à sua formação disciplinar. Daí, aliás, o diagnóstico nada alentador de que, no contexto atual, mais do que interdisciplinaridade, o que haveria atualmente seria uma espécie de "cacofonia" (ARNAUD, 1992, p. 20-21). Essa situação, explicitada por Arnaud, tendo por referência o contexto europeu de há mais de um quarto de século, infelizmente grassa no Brasil de hoje, onde, quando existente, o que se observa é, geralmente, uma "interdisciplinaridade de pacotilha". ${ }^{32}$

Diante disso, cabe incentivar o desenvolvimento dos "estudos sociojurídicos" como um "campo de pesquisa interdisciplinar". É, aliás, justamente o que propõem Arnaud e Fariñas Dulce que, renunciando a estruturar uma disciplina como local de fundação da pesquisa interdisciplinar, preferem referir-se a um "campo de estudos" no qual poderiam interagir múltiplas perspectivas acerca do direito. ${ }^{33}$ Por conseguinte, tornar-se-ia possível a conjugação estruturada dos mais diversos

\footnotetext{
${ }^{31}$ Segundo Arnaud (1992, p. 26), "au-delà des partitions disciplinaires, il devenait urgent de trouver de nouveaux fondements épistémologiques à une science dont l'objet ne pouvait être déterminé avec précision selon les données de l'épistémologie positiviste". Arnaud procura mapear o delineamento desses novos fundamentos epistemológicos em autores como Gaston Bachelard, Jean Piaget, Karl Popper e Thomas Kuhn, Jürgen Habermas, Michel Foucault e Pierre Bourdieu.

32 Por isso, Rouland (2018, p. 21), a partir de uma abordagem franco-brasileira, tem razão ao afirmar que "l'interdisciplinarité n'est bien souvent qu'un slogan".

${ }_{33}$ Referindo-se à possibilidade de desenvolvimento de pesquisas interdisciplinares, Arnaud e Fariñas Dulce (1998, p. 162-163) afirmam o seguinte: “oublions d'en faire une discipline et parlons provisoirement d'un champ d'étude. Dans ce champ, interviendront des regards croisés".
} 
ângulos de abordagem da regulação jurídica, tais como os da história, da sociologia, da ciência política, da psicologia, da economia, da antropologia, da psicologia social etc. A interação equilibrada dessas diversas perspectivas permitiria, como decorrência, tornar mais sofisticada a pesquisa sociojurídica. ${ }^{34}$ Portanto, os "estudos sociojurídicos" poderiam ser caracterizados como uma espécie de "mercado comum entre as ciências sociais", tal como proposto, há mais de meio século, pelo historiador Fernand Braudel (1958, p. 726).

Cumpre notar, ainda, que a caracterização dos "estudos sociojurídicos" como um campo, no sentido em que o concebem autores como Kurt Lewin e Pierre Bourdieu, $^{35}$ além de incentivar a pesquisa interdisciplinar, permite expandir a juridicidade para além do horizonte fixado pelos juristas positivistas. É nesse sentido que, retomando uma distinção veiculada desde o início da década de 1980, na obra Critique de la raison juridique: où va la sociologie du droit?, André-Jean Arnaud e María José Fariñas Dulce salientam que o campo recoberto pelos "estudos sociojurídicos" não se restringe apenas ao "direito" (droit), tal como definido pelos juristas, de modo a abarcar também os "sistemas jurídicos" (systèmes juridiques), que, em seu entendimento, consistiriam em modos de regulação e de resolução de conflitos, com qualidade jurídica, que, entretanto, não são propriamente o "direito", entendido como um "sistema jurídico" especial, uma vez que posto e imposto por uma autoridade legítima. ${ }^{36}$ Assumindo a distinção entre "direito" e "sistemas jurídicos", assim, como a pressuposição de que estes estão em interação, muitas vezes conflitiva e concorrencial, em um "campo jurídico vulgar" (champ juridique vulgaire),

${ }^{34}$ No contexto francês, essa empreitada é muito bem ilustrada pelas obras de André-Jean Arnaud e de Jacques Commaille, cofundadores do Réseau Droit et Société. A respeito, ver, especialmente: Arnaud $(1969 ; 1973 ; 1975 ; 1991)$, Commaille $(1994 ; 2015)$. No Brasil, cabe aludir, especialmente, à obra de José Eduardo Faria $(2018 ; 1988 ; 2002$, p. 53-130; 2010). Acerca do itinerário intelectual de José Eduardo Faria, ver Tavolari, Campilongo, Lima e Villas Bôas Filho (2018, p. 195-259).

35 André-Jean Arnaud e María José Fariñas Dulce (1998, p. 164-165), para caracterizarem a evolução do conceito de campo nas ciências sociais, aludem aos pensamentos de Jean Carbonnier, Kurt Lewin e, especialmente, ao de Pierre Bourdieu. No que tange ao “campo jurídico”, ver Bourdieu (1993, p. 9697; 1986a, p. 40-44; 1986b, p.03-19; 1991, p. 95-99; 2012, p. 300-335 e 511-533). Acerca do “campo jurídico" no pensamento de Pierre Bourdieu, ver, especialmente, Arnaud (1998, p. 33-36), García Villegas (2004, p. 57-70), Guibentif (2010, p. 272-299), Lascoumes e Le Bourhis (1996, p. 51-73), Lenoir (2004, p. 231-253), Sckell (2016, p. 157-178).

36 A respeito, ver, sobretudo, Arnaud (1981, p. 20-33; 1993, p. 147-167; 1989, p. 79-96) e Arnaud e Fariñas Dulce (1998, p. 166-167; 246-283).

37 Arnaud, em termos sintéticos, afirma que "le champ juridique vulgaire peut donc être défini comme celui des transformations pacifiques d'éléments d'un imaginaire en éléments de droit, moyennant 
compreende-se que o âmbito de abrangência dos "estudos sociojurídicos" seja bem mais amplo do que aquele englobado pela pesquisa jurídica convencional.

\section{AS CIÊNCIAS SOCIAIS COMO INSTRUMENTOS DE VIGILÂNCIA EPISTEMOLÓGICA NO ÂMBITO DOS “ESTUDOS SOCIOJURÍDICOS}

Inscritas no domínio dos "estudos sociojurídicos" - concebidos como "campo de pesquisa interdisciplinar", tal como definido supra -, as ciências sociais poderiam ser caracterizadas, sobretudo, como instrumentos de "vigilância epistemológica" - no sentido em que Bourdieu, Chamboredon e Passeron (2005, p. 95-120) a definem. Enquanto tal, elas proporcionariam um contributo crítico para evitar "as puras teorizações" e o "dogmatismo estéril" na abordagem dos juristas. ${ }^{38}$ Evidentemente que cada um dos diversos campos disciplinares colabora, à sua maneira, para essa "vigilância epistemológica". Assim, à guisa de exemplo, é possível afirmar que, se a pesquisa histórica se afigura, fundamentalmente, como instrumento de crítica ao anacronismo que, não raro, contamina as análises jurídicas, a antropologia, por seu turno, em virtude de sua atenção à alteridade e ao descentramento, apresentar-se-ia como uma ferramenta de grande importância ao desvelamento do etnocentrismo, entendido como "pressuposto da ausência de pressupostos" (BOURDIEU; CHAMBOREDON; PASSERON, 2005, p. 100), e a sociologia, como "perspectiva externa" de observação e descrição do direito, constituiria uma forma de apreensão do "ponto cego" das construções autorreflexivas desenvolvidas pelos juristas, sejam elas de maior ou de menor sofisticação. ${ }^{39}$

Contudo, como bem o notam Hugues Dumont e Antoine Bailleux, em seu "esboço de uma teoria das aberturas interdisciplinares acessíveis aos juristas", a possibilidade de uma pesquisa interdisciplinar realista implica que os juristas sejam capazes de se apropriar consistentemente de estudos desenvolvidos em outras áreas - tais como a antropologia, a economia, a história, a ciência política e a sociologia para o enriquecimento de suas próprias pesquisas. Todavia, e esse é um aspecto

une matérialisation qui s'est affirmée parallèle au droit en vigueur, et a sa concurrence" (ARNAUD, 1993, p. 160). A respeito, ver também Arnaud (1989, p. 88). Para um contraste entre Arnaud e Bourdieu acerca dessa noção, ver Capeller (2015, p. 18).

38 Arnaud (1992, p. 18) considera os "estudos sociojurídicos" como uma alternativa ao que designa de "pura teorização" e de "dogmatismo estéril".

${ }^{39}$ A respeito, ver, por exemplo, Arnaud e Fariñas Dulce (1998, p. 04-24), Black (1989, p. 21), Commaille (1988, p. 525-527), Luhmann (1993, p. 09-37 e 497-549), Arnaud (1986, p. 139-141), Ost e Van de Kerchove (1991, p. 72-76).

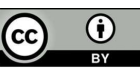


fundamental a se realçar, a utilização de contribuições de outras áreas não deve levar à suposição ingênua de que os juristas farão, eles mesmos, estudos de maior relevância no âmbito das diversas disciplinas pelas quais transitam no curso da empreitada interdisciplinar (DUMONT; BAILLEUX, 2010, p. 276-277). Isso significa que mobilizar aportes de outras áreas não converte o jurista em antropólogo, economista, filósofo, historiador, cientista político ou sociólogo. Simplesmente, habilita-o a desenvolver uma abordagem que, beneficiada pela interdisciplinaridade, seja capaz de compreender a regulação jurídica em termos mais sofisticados e consequentes.

No entanto, conceber as ciências sociais como instrumentos de "vigilância epistemológica" não implica outorgar-lhes um estatuto subalterno ou meramente ancilar no campo dos "estudos sociojurídicos"..$^{40}$ Portanto, não se está aqui a propor que se lhes atribua uma posição semelhante à que Jean Carbonnier, por exemplo, conferia à sociologia diante da "ciência do direito". ${ }^{41}$ Ao contrário, mediante a assunção de uma perspectiva construtivista, seria possível afirmar que os aportes das ciências sociais seriam decisivos na constituição do próprio objeto, uma vez que ele não é dotado de essencialidade prévia. Assim, entre outras coisas, as ciências sociais, entendidas nos termos aqui sugeridos, jogariam um papel ativo na construção crítica dos próprios critérios de fixação da juridicidade, de modo a permitir a superação do "dogmatismo estéril", da "teorização pura" e da contaminação pelo "saber espontâneo" dos juristas, ou seja, pelo senso comum (ARNAUD; FARIÑAS DULCE,

40 Trata-se de uma visão recorrente mesmo entre eminentes juristas brasileiros. Tercio Sampaio Ferraz Jr. (2003, p. 47), por exemplo, referindo-se a disciplinas que ele, com base em Theodor Viehweg, classifica como zetéticas, em meio às quais está a sociologia jurídica, observa que "elas são tidas como auxiliares da ciência jurídica stricto sensu". No mesmo sentido, ver Oliveira (2015, p. 172). Acerca do desenvolvimento da sociologia jurídica no Brasil, ver, especialmente Faria e Campilomgo (1991, p. 25 e ss.), Junqueira (1993, p. 17 e ss.), Souto e Souto (2003, p. 111 e ss.), Lopes e Freitas Filho (2014, p. 91-103), García Villegas (2015, p. 318-332).

41 A respeito, Jacques Commaille (1988, p. 253-265) critica a instrumentalização da sociologia como uma espécie de maidservant pelos juristas. Ainda pouco difundida no Brasil, a "sociologia política do direito" proposta por Commaille (1994, p. 17-36), afigura-se como uma proposta interdisciplinar de grande potencial heurístico. A respeito, ver Commaille (2013, p. 929-933 ; 2015, p. 11-38 e 381-402; 2016 , p. $01-12$; 2018, p. 1270-1277). Sobre a "sociologia política do direito", proposta por esse autor, ver, especialmente Arnaud (1998, p.36-38), García Villegas (2015, p. 291-302), García Villegas e Lejeune (2011, p. 16-19), Villas Bôas Filho (2015a, p. 56-75; 2018a, p. 268-277). 
1998, p. 261-263; DUPRET, 2003, p. 87; 2005, p. 159-172; 2010, p. 325; 2016, p. 658-661, 2016). ${ }^{42}$

O papel desempenhado pelas ciências sociais nos "estudos sociojurídicos" é, ademais, fundamental na própria estruturação da empiria. Nesse particular, para jogar com as palavras, é preciso notar que, no âmbito da pesquisa empírica, o "dado" não é dado, e sim construído. ${ }^{43}$ Conceber o "dado" como desde logo dado implica a adesão ingênua do analista à suposta imanência do objeto ao real. Por esse motivo, José Reinaldo de Lima Lopes e Roberto Freitas Filho (2014, p. 99) têm plena razão ao afirmarem que considerar os "dados jurídicos" como "fatos brutos" acarreta a perda da força crítica e interpretativa da investigação empírica. ${ }^{4}$ Aliás, como bem observam Antoine Bailleux e François Ost (2013, p. 37-38), o "direito" não é um objeto estabelecido a priori, dotado de certa substancialidade natural. Compreendê-lo como tal significa assumir uma pressuposição naïve que, pautada por postulados ontológicos, conduz à ideia de que a realidade seria, em si, dividida em domínios ou campos preestabelecidos naturalmente. ${ }^{45}$ Não é necessário dissertar longamente acerca do quanto esse tipo de visão é vulnerável à contaminação por representações de senso comum. É para elidir esse tipo de concepção que as ciências sociais, como instrumentos de "vigilância epistemológica", ao interagirem no âmbito dos "estudos sociojurídicos", concebido como um campo aberto para a investigação interdisciplinar, se fazem fundamentais. ${ }^{46}$ Assim, seu estatuto se altera: de ancilares, como outrora consideradas, passam a ser centrais.

\footnotetext{
42 Acerca dessa questão, ver também Serverin (2000, p. 64-69).

${ }^{43}$ Pierre Bourdieu, Jean-Claude Chamboredon e Jean-Claude Passeron $(2005,24)$ ressaltam que "poser avec Bachelard que le fait scientifique est conquis, construit, constaté, c'est récuser à la fois l'empirisme qui réduit l'acte scientifique à un constat et le conventionnalisme qui lui oppose seulement le préalable de la construction". Como bem observa Frédéric Lebaron (2012, p. 112) , "le principal 'message', parfois simplifié, que l'on retiendra du Métier de sociologue est qu'il y a pas d'empirie sans théorie [...]". A respeito, ver Jourdain e Naulin (2011, p. 21).

${ }^{44}$ A respeito, ver também Oliveira (2015, p. 170).

${ }_{45}$ No mesmo sentido, ver Ost e Van de Kerchove (1991, p. 69).

46 Essa empreitada inspira-se diretamente na ideia de "reflexividade" como expressão de uma "epistemologia crítica", tal como a concebe e mobiliza Pierre Bourdieu. A respeito, ver, especialmente Bourdieu (2001, p. 173-223). Sobre a questão da "reflexividade" no pensamento de Bourdieu, ver, por exemplo, Deer (2018, p. 253-269) , Gingras (2004, p. 337-347).
} 


\section{CONCLUSÃO}

Pretendeu-se ressaltar, neste artigo, a importância da pesquisa interdisciplinar para a compreensão da regulação jurídica em um contexto social marcado pela hipercomplexidade. ${ }^{47}$ Para tanto, preliminarmente, foram apontados os desafios enfrentados por esse tipo de pesquisa que, em virtude das dificuldades que lhe são inerentes, pode oscilar entre uma situação de "cacofonia" ou de "caricatura". Diante de tais reptos, foram discutidas, em seguida, as premissas indispensáveis para o desenvolvimento de uma pesquisa interdisciplinar consistente. Nesse sentido, mobilizando-se, especialmente, a proposta de François Ost e Antoine Bailleux, procurou-se ressaltar que a superação dos "modelos ingênuos", fundados em pressupostos ontológicos, mediante a assunção de uma perspectiva construtivista que conduz à elaboração de "modelos críticos", é fundamental ao desenvolvimento dessa empreitada.

Contudo, com o intuito de destacar os limites da pesquisa interdisciplinar, foi feita uma breve alusão à pretensão de Hugues Dumont e Antoine Bailleux de esboçar "uma teoria das aberturas interdisciplinares acessíveis aos juristas" em que os autores procuram delinear o que seria uma "abertura interdisciplinar realista". Como visto, apesar de enfatizarem a importância de os juristas se valerem de estudos desenvolvidos nas mais diversas áreas das ciências sociais, Dumont e Bailleux salientam, todavia, que essa apropriação não implica supor que os juristas possam desconsiderar a especificidade de sua perspectiva e imaginar que desenvolverão, eles mesmos, estudos de maior relevância no âmbito das diversas disciplinas pelas quais transitam. Sem reconstruir mais pormenorizadamente a "ciência interdisciplinar e crítica do direito" por eles proposta, procurou-se apenas explicitar que eles, inspirando-se em André-Jean Arnaud, a concebem como uma "science du droitcarrefour interdisciplinaire".

Feitas essas considerações, mobilizou-se a proposta de André-Jean Arnaud e María José Fariñas Dulce para, a partir dela, conceber os "estudos sociojurídicos" como um campo interdisciplinar em que contribuições provenientes das mais diversas áreas das ciências sociais podem ser apropriadas pelos juristas para a obtenção de uma compreensão mais sofisticada da regulação jurídica. Ressaltou-se, ademais, que a caracterização dos "estudos sociojurídicos" nesses termos, além de

\footnotetext{
${ }^{47}$ Acerca do caráter hipercomplexo da sociedade contemporânea, ver, especialmente, Luhmann (2007, p. 315 e 706-707). A respeito, vale notar que Edgar Morin (2005, p. 51) propõe a noção de hipercomplexidade para a consideração do "problema humano".
}

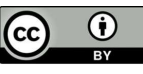


estimular a pesquisa interdisciplinar, permite expandir a juridicidade para além do horizonte fixado pelos juristas positivistas, de modo a incentivar a explicitação de seu enraizamento social. ${ }^{48}$ Por fim, sustentou-se que, no âmbito dos "estudos sociojurídicos", as ciências sociais poderiam ser entendidas como instrumentos de "vigilância epistemológica", no sentido em que a definem Pierre Bourdieu, JeanClaude Chamboredon e Jean-Claude Passeron.

\section{REFERÊNCIAS}

ARNAUD, André-Jean. Critique de la raison juridique 1. Où va la sociologie du droit? Paris: LGDJ, 1981.

ARNAUD, André-Jean. Critique de la raison juridique 2. Gouvernants sans frontières. Entre mondialisation et post-mondialisation. Paris: LGDJ, 2003.

ARNAUD, André-Jean. De la régulation par le droit à l'heure de la globalisation. Quelques observations critiques. Droit et Société, no 35, p. 11-35, 1997.

ARNAUD, André-Jean. Droit et Société: du constat à la construction d'un champ commun. Droit et Société, no 20-21, p. 17-38, 1992.

ARNAUD, André-Jean. Droit et société: un carrefour interdisciplinaire. Revue Interdisciplinaire d'Études Juridiques, v. 21, p. 7-32, 1988.

ARNAUD, André-Jean. Droit: le système et l'ensemble. In: ARNAUD, André-Jean; GUIBENTIF, Pierre (Org.). Niklas Luhmann observateur du droit. Paris: LGDJ, 1993, p. $147-167$.

48 Nesse particular, Delpeuch, Dumoulin e Galembert (2014, p. 10), aludindo à perspectiva de Baudouin Dupret, asseveram que "selon une formule célèbre d'A. Sarat, 'the law is all over'. [...] Cette ubiquité sociale du droit n'est d'ailleurs pas pour rien dans la forte interdisciplinarité des sociolegal studies: droit et sociologie y voisinent avec l'anthropologie, l'histoire, l'économie, la linguistique, la psychologie, et la philosophie". Nesse particular, as obras de André-Jean Arnaud, Jacques Commaille e Étienne Le Roy se afiguram como modelares. Em meio a elas, ver, especialmente: Aarnaud (1981; 2003; 2004; 1991), Arnaud e Fariñas Dulce (1998), Commaille (2015; 2016, p. 01-12), Le Roy $(1999 ; 2007$, p. 341-351). 
ARNAUD, André-Jean. Du jeu fini au jeu ouvert. Réflexions additionnelles sur le Droit post-moderne. Droit et Société, no 17-18, p. 39-55, 1991 (1991a).

ARNAUD, André-Jean. Entre modernité et mondialisation. Leçons d'histoire de la philosophie du droit et de l'État. 2ème édition. Paris: LGDJ, 2004.

ARNAUD, André-Jean. Essai d'analyse structurale du Code Civil français. La règle du jeu dans la paix bourgeoise. Paris: LGDJ, 1973.

ARNAUD, André-Jean. Jean Carbonnier. Un juriste dans la cité. Paris: LGDJ, 2012.

ARNAUD, André-Jean. La gouvernance. Un outil de participation. Paris: LGDJ, 2014.

ARNAUD, André-Jean. La valeur heuristique de la distinction interne/externe comme grande dichotomie pour la connaissance du droit: éléments d'une démystification. Droit et Société, n. 2, p. 139-141, 1986.

ARNAUD, André-Jean. Le Droit: un ensemble peu convivial. Droit et Société, n. 1112, p. 79-96, 1989.

ARNAUD, André-Jean. Le droit comme produit. Présentation du dossier sur la norme de la production juridique. Droit et Société, n. 27, p. 293-301, 1994.

ARNAUD, André-Jean. Le droit trahi para la sociologie. Une pratique de l'histoire. Paris: LGDJ, 1998.

ARNAUD, André-Jean. Les juristes face à la société. Du XIXe siècle à nos jours. Paris: PUF, 1975.

ARNAUD, André-Jean. Les origines doctrinales du Code Civil français. Paris: LGDJ, 1969.

ARNAUD, André-Jean. O direito traído pela filosofia. Tradução de Wanda de Lemos Capeller e Luciano Oliveira. Porto Alegre: Fabris, 1991 (1991b). 
ARNAUD, André-Jean. Pour une pensée juridique européenne. Paris: PUF, 1991 (1991c).

ARNAUD, André-Jean. Regards croisés sur la notion de droit en contexte. Revue Interdisciplinaire d'Études Juridiques, v. 70, p. 45-53, 2013.

ARNAUD, André-Jean; FARIÑAS DULCE, María José. Introduction à l'analyse sociologique des systèmes juridiques. Bruxelles: Bruylant, 1998.

BAILLEUX, Antoine; OST, François. Droit, contexte et interdisciplinarité: refondation d'une démarche. Revue Interdisciplinaire d'Études Juridiques, v. 70, n. 1, p. 25-44, 2013.

BLACK, Donald. Sociological justice. New York: Oxford University Press, 1989.

BOURDIEU, Pierre. Esprits d'État [Genèse et structure du champ bureaucratique]. Actes de la Recherche en Sciences Sociales, v. 96-97, p. 49-62, Mars. 1993.

BOURDIEU, Pierre. Habitus, code et codification. Actes de la Recherche en Sciences Sociales, v. 64, p. 40-44, Sept. 1986 (1986a).

BOURDIEU, Pierre. La force du droit. Éléments pour une sociologie du champ juridique. Actes de la Recherche en Sciences Sociales, v. 64, p. 3-19, Sept. 1986 (1986b).

BOURDIEU, Pierre. Les juristes, gardiens de l'hypocrisie collective. In: CHAZEL, François; COMMAILLE, Jacques. Normes juridiques et régulation sociale. Paris: LGDJ, 1991, p. 95-99.

BOURDIEU, Pierre. Science de la science et réflexivité. Paris: Raisons d'agir, 2001.

BOURDIEU, Pierre. Sur l'État. Cours au Collège de France 1989-1992. Paris: Seuil, 2012.

BOURDIEU, Pierre; CHAMBOREDON, Jean-Claude; PASSERON, Jean-Claude. Le

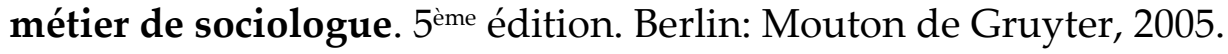


BRAUDEL, Fernand. Histoire et sciences sociales: la longue durée. Annales. Économies, Sociétés, Civilisations, n. 4, p. 725-753, 1958.

CAILLOSSE, Jacques. La sociologie politique du droit, le droit et les juristes. Droit et Société, no7, p. 187-206, 2011.

CAMPILONGO, Celso Fernandes. Direito e democracia. $2^{\underline{a}}$ edição. São Paulo: Max Limonad, 2000 (2000a).

CAMPILONGO, Celso Fernandes. O direito na sociedade complexa. São Paulo: Max Limonad, 2000 (2000b).

CAPELLER, Wanda. De que lugar falamos? Retomando um velho papo sobre o Direito e a Sociologia. Revista de Estudos Empíricos em Direito, v. 2, n. 2, p. 10-25, jan. 2015.

CARBONNIER, Jean. Sociologie juridique. $2^{\mathrm{ème}}$ édition. Paris: PUF, 2008.

CHEVALLIER, Jacques. Doctrine juridique et science juridique. Droit et Societe, $\mathrm{n}^{\mathrm{o}}$ 50, p. 103-120, 2002.

COMMAILLE, Jacques. À quoi nous sert le droit? Paris: Gallimard, 2015.

COMMAILLE, Jacques. À quoi nous sert le droit pour comprendre sociologiquement les incertitudes des sociétés contemporaines? SociologieS [En ligne], Dossiers, Sociétés en mouvement, p. 1-12, 2016. Disponível em: <http://sociologies.revues.org/5278>. Acesso em: 7 mar. 2016.

COMMAILLE, Jacques. De la "sociologie juridique" à une sociologie politique du droit. In: COMMAILLE, Jacques; DUMOULIN, Laurence; ROBERT, Cécile (Dir.). La juridicisation du politique. Paris: LGDJ, 2010, p. 29-51.

COMMAILLE, Jacques. La construction d'une sociologie spécialisée. Le savoir sociologique et la sociologie juridique de Jean Carbonnier. L'Année Sociologique, v. 57, n. 2, p. 275-299, 2007. 
COMMAILLE, Jacques. Les nouveaux enjeux épistémologiques de la mise en contexte du droit. Revue Interdisciplinaire d'Études Juridiques, v. 70, n. 1, p. 62-69, 2013 (2013a).

COMMAILLE, Jacques. L'esprit sociologique des lois: essai de sociologie politique du droit. Paris: PUF, 1994.

COMMAILLE, Jacques. L'interdisciplinarité aux regards de la sociologie (opinion sur François Ost et Michel Van de Kerchove, Jalons pour une théorie critique du droit. Bruxelles, Bruylant, 1987). Droit et Société, n. 10, p. 525-527, 1988 (1988a).

COMMAILLE, Jacques. The law and science: dialectics between the prince and the maidservant. Law \& Policy, v. 10, n. 2, p. 253-265, Apr.-Jul. 1988 (1988b).

COMMAILLE, Jacques. Repenser la légalité. La Semaine Juridique - édition générale, n. 26, p. 1270-1277, juin 2018.

COMMAILLE, Jacques. Uma sociologia política do direito. Revista da Faculdade de Direito da USP, v. 108, p. 929-933, jan.-dez. 2013 (2013b).

DEER, Cécile. Reflexividade. In: GRENFELL, Michael. Pierre Bourdieu: conceitos fundamentais. Petrópolis: Vozes, 2018, p. 253-269.

DELMAS-MARTY, Mireille. Les forces imaginantes du droit (II). Le pluralisme ordonné. Paris: Seuil, 2006.

DELMAS-MARTY, Mireille. Libertés et sûreté dans le monde dangereux. Paris: Seuil, 2010.

DÉLOYE, Yves. Sociologie historique du politique. 3ème éditon. Paris: La Découverte, 2007.

DELPEUCH, Thierry; DUMOULIN, Laurence; GALEMBERT, Claire de. Sociologie du droit et de la justice. Paris: Armand Colin, 2014. 
DUMONT, Hugues; BAILLEUX, Antoine. Esquisse d'une théorie des ouvertures interdisciplinaires accessibles aux juristes. Droit et Société, n. 75, p. 275-293, 2010.

DUPRET, Baudouin. Droit et sciences sociales: Pour une respécification praxéologique. Droit et Société, n. 75, p. 315-335, 2010.

DUPRET, Baudouin. La nature plurale du droit. Cahiers d'anthropologie du droit. Les pluralismes juridiques. Paris: Karthala, 2003, p. 81-93.

DUPRET, Baudouin. Réflexions sur le concept de droit à partir de quelques cas limites. Droit et Société, n. 94, p. 645-661, 2016.

DUPRET, Baudouin. What is plural in the law? A praxiological answer. Égypte/Monde Arabe, $3^{\text {rd }}$ serie, n. 1, p. 159-172, 2005.

FARIA, José Eduardo. Baú de ossos de um sociólogo do direito. Curitiba: Juruá, 2018.

FARIA, José Eduardo. Eficácia jurídica e violência simbólica: o direito como instrumento de transformação social. São Paulo: Edusp, 1988.

FARIA, José Eduardo. Estado, sociedade e direito. In: FARIA, José Eduardo; KUNTZ, Rolf. Qual o futuro dos direitos? Estado, mercado e justiça na reestruturação capitalista. São Paulo: Max Limonad, 2002, p. 53-130.

FARIA, José Eduardo. Sociologia jurídica: direito e conjuntura. São Paulo: Saraiva, 2010.

FARIA, José Eduardo; CAMPILONGO, Celso Fernandes. A sociologia jurídica no Brasil. Porto Alegre: Fabris, 1991.

FERRAZ JUNIOR, Tercio Sampaio. Introdução ao estudo do direito: técnica, decisão, dominação. 4. ed. São Paulo: Atlas, 2003.

GARCÍA VILLEGAS, Mauricio. Les pouvoirs du droit. Analyse comparée d'études sociopolitiques du droit. Paris: LGDJ, 2015. 
GARCÍA VILLEGAS, Mauricio. On Pierre Bourdieu's Legal Thought. Droit et Société, n. 56-57, p. 57-70, 2004.

GARCÍA VILLEGAS, Mauricio; LEJEUNE, Aude. La sociologie du droit en France: de deux sociologies à la création d'un projet pluridisciplinaire. Revue Interdisciplinaire d'Études Juridiques, v. 66, n. 1, p. 1-39, 2011.

GINGRAS, Yves. Réflexivité et sociologie de la connaissance scientifique. In: PINTO, Louis; SAPIRO, Gisèle; CHAMPAGNE, Patrick. Pierre Bourdieu, sociologue. Paris: Librairie Arthème Fayard, 2004, p. 337-347.

GONÇALVES, Guilherme Leite; VILLAS BÔAS FILHO, Orlando. Teoria dos sistemas sociais: direito e sociedade na obra de Niklas Luhmann. São Paulo: Saraiva, 2013.

GUIBENTIF, Pierre. Foucault, Luhmann, Habermas, Bourdieu: une génération repense le droit. Paris: LGDJ, 2010.

HARDT, Michael; NEGRI, Antonio. Empire. Cambridge, Massachusetts: Harvard University Press, 2000.

HESPANHA, António Manuel. Cultura jurídica europeia: síntese de um milénio. Coimbra: Almedina, 2012.

JOURDAIN, Anne; NAULIN, Sidonie. La théorie de Pierre Bourdieu et ses usages sociologiques. Paris: Armand Colin, 2011.

JUNQUEIRA, Eliane Botelho. A sociologia do direito no Brasil: introdução ao debate atual. Rio de Janeiro: Lumen Juris, 1993.

LASCOUMES, Pierre; LE BOURHIS, Jean-Pierre. Des 'passe-droits' aux passes du droit. La mise en œuvre socio-juridique de l'action publique. Droit et Société, n. 32, p. 51-73,1996. 
LE ROY, Étienne. Le jeu des lois. Une anthropologie “dynamique” du Droit. Paris: LGDJ, 1999.

LE ROY, Étienne. Le tripode juridique. Variations anthropologiques sur un thème de flexible droit. L'Année Sociologique, v. 57, n. 2, p. 341-351, 2007.

LE ROY, Étienne. Place de la juridicité dans la médiation. Jurisprudence - Revue Critique, no 4 (La médiation. Entre renouvellement de l'offre de justice et droit), p. 193-208, 2013.

LEBARON, Frédéric. Le métier de sociologue. Préalables épistémologiques. In: LEBARON, Frédéric; MAUGER, Gérard (Dir.). Lectures de Bourdieu. Paris: Ellipses, 2012, p. 111-121.

LENOIR, Remi. Du droit au champ juridique. In: PINTO, Louis; SAPIRO, Gisèle; CHAMPAGNE, Patrick. Pierre Bourdieu, sociologue. Paris: Librairie Arthème Fayard, 2004, p. 231-253.

LOPES, José Reinaldo de Lima; FREITAS FILHO, Roberto. Law and society in Brazil at the crossroads: a review. Annual Review of Law and Social Science, v. 10, p. 91103, 2014.

LUGAN, Jean-Claude. La systémique sociale. $5^{\mathrm{e}}$ édition. Paris: Presses Universitaires de France, 2012.

LUHMANN, Niklas. Das Recht der Gesellschaft. Frankfurt am Main: Suhrkamp, 1993 [trad. port. O direito da sociedade. São Paulo: Martins Fontes, 2016].

LUHMANN, Niklas. La sociedad de la sociedad. Tradução de Javier Torres Nafarrate. México: Editorial Herder, 2007.

LUHMANN, Niklas. Social systems. Translated by Eva M. Knodt. Stanford, California: Stanford University Press, 1995.

MOORE, Sally Falk. Legal Pluralism as Omnium Gatherum. FIU Law Review, v. 10, no 1, p. 5-18, 2014. 
MORIN, Edgar. Introduction à la pensée complexe. Paris: Éditions du Seuil, 2005.

OLIVEIRA, Luciano. Manual de sociologia jurídica. Petrópolis: Vozes, 2015.

OST, François. In memoriam - André-Jean Arnaud (1936-2015). Revue Interdisciplinaire d'Études Juridiques, v. 76, p. 1-3, 2016.

OST, François. Le droit comme traduction. Québec: Presses de l'Université de Laval, 2009.

OST, François; VAN DE KERCHOVE, Michel. De la scène au balcon. D'où vient la science du droit? In: CHAZEL, François; COMMAILLE, Jacques. Normes juridiques et régulation sociale. Paris: LGDJ, 1991, p. 67-80.

PIERET, Julien. Droit, contexte et changement social dans la théorie des systèmes sociaux. Revue Interdisciplinaire d'Études Juridiques, v. 70, n. 1, p. 139-148, 2013.

ROULAND, Norbert. Anthropologie juridique. Paris: PUF, 1988.

ROULAND, Norbert. L'anthropologie juridique. Paris: PUF, 1995.

ROULAND, Norbert. Nos confins do direito. Tradução de Maria Ermantina de Almeida Prado Galvão. São Paulo: Martins Fontes, 2003.

ROULAND, Norbert. Retour du Brésil: impressions d'un juriste anthropologue français. Paris: L'Harmattan, 2018.

SANTOS, Boaventura de Sousa. Para um novo senso comum: a ciência, o direito e a política na transição paradigmática. A crítica da razão indolente: contra $o$ desperdício da experiência. $4^{a}$ ed. São Paulo: Cortez, 2002. v. 1.

SCKELL, Soraya Nour. Os juristas e o direito em Bourdieu. A conflituosa construção histórica da racionalidade jurídica. Tempo social, Revista de Sociologia da USP, v. 28, nº 1, 157-178, 2016. 
SERVERIN, Évelyne. Sociologie du droit. Paris: Éditions la Découverte, 2000.

SOUTO, Cláudio; SOUTO, Solange. Sociologia do direito: uma visão substantiva. $3^{\mathrm{a}}$ ed. Porto Alegre: Fabris, 2003.

TAVOLARI, Bianca; CAMPILONGO, Celso Fernandes; LIMA, Fernando Rister de Sousa; VILLAS BÔAS FILHO, Orlando. Entrevista com o Professor José Eduardo Faria (Parte I). Revista Brasileira de Sociologia do Direito, v. 5, n. 2, p. 195-259, maio-ago. 2018.

TEUBNER, Gunther. How the law thinks: toward a constructive epistemology of law. Law and Society Review, v. 23, n. 5, p. 727-757, 1989.

VANDERLINDEN, Jacques. Anthropologie juridique. Paris: Dalloz, 1995.

VANDERLINDEN, Jacques. Les Pluralismes juridiques. In: RUDE-ANTOINE, Edwige; CHRÉTIEN-VERNICOS, Geneviève (Coord.). Anthropologies et droits: état des savoirs et orientations contemporaines. Paris: Dalloz, 2009, p. 25-76.

VILLAS BÔAS FILHO, Orlando. A governança em suas múltiplas formas de expressão: o delineamento conceitual de um fenômeno complexo. Revista Estudos Institucionais, v. 2, no 2, p. 670-706, 2016 (2016a).

VILLAS BÔAS FILHO, Orlando. A juridicização e a judiciarização enfocadas a partir da "sociologia política do direito" de Jacques Commaille. Revista Brasileira de Sociologia do Direito, v. 2, no 2, p. 56-75, jul.-dez. 2015 (2015a).

VILLAS BÔAS FILHO, Orlando. A mediação em um campo de análise interdisciplinar: o aporte da teoria do multijuridismo de Étienne Le Roy. Revista Estudos Institucionais, v. 3, no 2, p. 1112-1162, 2017 (2017a).

VILLAS BÔAS FILHO, Orlando. A questão da universalidade das categorias jurídicas ocidentais a partir da abordagem antropológica: nota sobre a discussão entre Max Gluckman e Paul Bohannan. Revista da Faculdade de Direito da USP, v. 110, p. 277-318, jan.-dez. 2015 (2015b). 
VILLAS BÔAS FILHO, Orlando. A regulação jurídica para além de sua forma ocidental de expressão: uma abordagem a partir de Étienne Le Roy. Revista Direito \& Práxis, v. 6, n. 12, p. 159-195, 2015 (2015c).

VILLAS BÔAS FILHO, Orlando. André-Jean Arnaud: l'homme derrière l'œuvre. Revista da Faculdade de Direito da USP, v. 112, p. 323-343, jan.-dez. 2017 (2017b).

VILLAS BÔAS FILHO, Orlando. Juridicidade: uma abordagem crítica à monolatria jurídica enquanto obstáculo epistemológico. Revista da Faculdade de Direito da USP, v. 109, p. 314-317, jan.-dez. 2014.

VILLAS BÔAS FILHO, Orlando. O direito de qual sociedade? Os limites da descrição sociológica de Niklas Luhmann acerca do direito a partir da crítica antropológica. In: FEBBRAJO, Alberto; LIMA, Fernando Rister de Sousa; PUGLIESI, Márcio (Coord.). Sociologia do direito: teoria e práxis. Curitiba: Juruá, 2015 (2015d), p. 341-370.

VILLAS BÔAS FILHO, Orlando. O direito como revelador das transformações sociais contemporâneas: a abordagem sociopolítica de Jacques Commaille. Revista Direito GV, v. 14, n. 1, p. 268-277, jan.-abr. 2018 (2018a).

VILLAS BÔAS FILHO, Orlando. O impacto da governança sobre a regulação jurídica contemporânea: uma abordagem a partir de André-Jean Arnaud. REDES - Revista Eletrônica Direito e Sociedade, v. 4, n. 1, p. 145-171, 2016 (2016b).

VILLAS BÔAS FILHO, Orlando. Por um delineamento conceitual da complexidade social: as experiências do Mercosul e do orçamento participativo na análise de André-Jean Arnaud sobre a governança. Novos Estudos Jurídicos, v. 23, n 2, p. 491520, 2018 (2018b). 